\title{
A MÚSICA COMO RECURSO PEDAGÓgICO: A REPRESENTAÇÃO DOS BOMBARDEIOS AÉREOS DA 2a GUERRA MUNDIAL NAS LETRAS DE HEAVY METAL
}

\section{MUSIC AS A TEACHING RESOURCE: A REPRESENTATION OF THE AERIAL BOMBARDMENTS OF WORLD WAR 2 IN THE LYRICS OF HEAVY METAL}

\author{
Caroline Loise Dähne ${ }^{1}$ \\ Jonathan de Oliveira Molar ${ }^{2}$
}

\begin{abstract}
RESUMO: Atualmente as discussões que permeiam o uso de recursos pedagógicos no ensino de história têm demonstrado a importância da utilização de músicas nas aulas para que os conceitos espontâneos dos alunos sejam aproveitados na construção de conceitos científicos. O presente trabalho se estrutura a partir da experiência da aplicação de um material didático tendo a música como recurso, cujo tema foi a representação dos bombardeios aéreos da $2^{a}$ Guerra mundial nas letras de Heavy Metal, que foi utilizado em um mini-curso destinado a um grupo de alunos do 30 ano do ensino médio. As respostas dos alunos são o objeto de análise deste artigo que visa perceber se os objetivos iniciais que orientaram a elaboração do material didático e sua aplicação foram alcançados.
\end{abstract}

Palavras-chave: História e Música. Ensino de História. 2a Guerra Mundial.

\begin{abstract}
Currently the discussions that permeate the use of teaching resources in the education of history have shown the importance of using music in the classroom so that students' spontaneous concepts are utilized in the construction of scientific concepts. This work is structured from the experience of the application of didactic material having music as a resource, whose theme was the representation of aerial bombardments of the 2nd World War in the lyrics of heavy metal, that was used in a mini-course designed to a group of students from the 3rd year of high school. Student responses are the object of analysis in this article aims to understand whether the initial goals that guided the preparation of teaching materials and their application have been achieved.
\end{abstract}

Keywords: History and Music. Teaching of History. World War 2.

\footnotetext{
${ }^{1}$ Universidade Estadual de Ponta Grossa. Prefeitura Municipal de Ponta Grossa.

2 Graduado em História pela UEPG, mestre em Educação pela UEPG e Doutorando em Educação pela UFPR.
} 


\section{Introdução}

A ideia para a elaboração desse estudo partiu de uma atividade desenvolvida na disciplina de Oficina de História $V$ do curso de Licenciatura em História da Universidade Estadual de Ponta Grossa, que tem como objetivo final a elaboração de uma pesquisa de intervenção na área educacional, para isso, foi confeccionado um material didático destinado a alunos do $3^{\circ}$ ano do ensino médio e aplicado um minicurso.

Buscando a integração entre o conhecimento escolar com os recursos pedagógicos, o material didático se desenvolveu a partir da análise de duas músicas de Heavy Metal que abordam questões sobre os bombardeios aéreos na $2^{a}$ Guerra Mundial, tema presente no currículo escolar de História. Essas músicas foram: Aces High da banda Iron Maiden e Bomber da banda Mötorhead.

O material didático consistiu em uma cartilha com textos explicativos sobre a $2^{a}$ Guerra Mundial, o papel dos bombardeios aéreos nessa guerra, a história do Heavy Metal, a história das bandas selecionadas- Iron Maiden e Mötorhead - a análise das músicas e suas letras, e os exercícios propostos.

O minicurso foi ministrado em setembro de 2011, no Instituto de Educação Professor César Prieto Martinez, direcionado a um grupo de alunos do $3^{\circ}$ ano do ensino médio. Ao longo de três aulas foi exposto o tema a partir do material didático produzido e foram realizados os exercícios propostos. Esses exercícios são o objeto de análise do presente estudo, que visa através dos apontamentos dos alunos perceber se os objetivos iniciais que orientaram a elaboração do material didático e sua aplicação foram alcançados.

O presente artigo está estruturado em cinco seções que buscam elucidar os conteúdos abordados no material didático e justificar a importância da utilização de músicas como recurso pedagógico nas aulas de História. A primeira seção destina-se a trabalhar os aspectos referentes ao contexto histórico do material didático, para tal são apresentadas as principais características da Segunda Guerra Mundial. 
A segunda seção do artigo busca apresentar o recorte temático do material didático, ou seja, os bombardeios aéreos da Segunda Guerra Mundial, destacando os aspectos destrutivos ocasionados pela tecnologia de aviação bélica que havia se aperfeiçoado em relação à Primeira Guerra Mundial. A terceira e a quarta seção desse artigo tratam especificamente da parte musical, relacionamos a utilização de músicas no ensino de história com a importância de se trabalhar elementos do cotidiano dos alunos na construção de um saber histórico escolar. Na quarta seção são apontadas algumas características musicais do Heavy Metal.

A última seção desse artigo destina-se a análise das respostas dos exercícios propostos aos alunos, é com base nessas respostas que buscamos compreender se os objetivos iniciais da elaboração do material didático foram alcançados.

\section{O contexto histórico do material didático: a 2a Guerra Mundial}

A Segunda Guerra Mundial (1939-1945) é considerada, por muitos historiadores, uma grande catástrofe, já que seus números de destruição foram gigantescos. Estima-se que foram em média 50 a 60 milhões de mortos, além de aproximadamente 28 milhões de mutilados, sendo que grande parte desse contingente eram civis.

Para o historiador Eric Hobsbawm (1995), o período entre o início da Primeira Guerra Mundial e o término da Segunda foi de grande calamidade, pois abalou mundialmente a economia e o modo de vida das pessoas. Em seu livro Era dos Extremos, o autor nomeia esse período a Era de Catástrofe e aponta que uma característica das guerras modernas do século XX é envolver a sociedade como um todo, o que ele chama de "Guerra de Massas". (HOBSBAWM, 1995, p. 51)

No período após a Primeira Guerra a Alemanha estava insatisfeita com os acordos do Tratado de Versalhes assinado em junho de 1919, o qual determinava que deveria pagar uma alta indenização, ter suas forças armadas reduzidas e devolver alguns territórios que haviam sido 
conquistados por eles. Na década de 1920 com a crise econômica e a queda da Bolsa de Nova York em 1929, a economia mundial foi abalada, gerando desemprego e falência de bancos e empresas. De acordo com Mocelin, "A crise da Bolsa significou, definitivamente, o choque do capitalismo." (MOCELIM, 2009, p.4).

Na mesma década se dá a formação dos Estados Totalitários, com o Fascismo na Itália e o Nazismo na Alemanha, possibilitando o fortalecimento desses países economicamente. Esses regimes totalitários se caracterizavam principalmente pelo governo autoritário e pela unidade do Estado, que controlava a sociedade. Com a exacerbação do nacionalismo, esses regimes passaram a desvalorizar aquilo que é de fora, no caso da Alemanha isso é demonstrado na busca da pureza racial que seria a Raça Ariana, o que acabou culminando no Holocausto, com a morte de aproximadamente de quatro a seis milhões de pessoas.

A criação do conceito de totalitarismo nasceu da necessidade de identificar a nova forma de regime que surgiu no século XX, não-enquadrável nas antigas designações de "despotismo" ou de "tirania", de tal modo que a palavra nasceu da coisa. A coisa corresponde à instituição de regimes que visam a sujeitar a sociedade nos moldes de um Partido-Estado, cujo chefe é fundamental, seja no sentido da referida constituição do Partido-Estado, seja no estabelecimento de laços emotivos com as massas, a partir de uma figura carismática. (FAUSTO, 2001, p. 7)

Hobsbawm (1995) aponta que "as três potências descontentes" Alemanha, Itália e Japão estavam ligadas por diversos tratados desde 1930. No dia $1^{0}$ de setembro de 1939 a Alemanha utiliza da tática da Blitzkrieg (guerra relâmpago) e invade a Polônia, dois dias depois dessa ação a GrãBretanha e a França que a apoiavam, declaram guerra à Alemanha, iniciando assim o conflito.

Durante os anos de conflito, existiram grandes confrontos marcados, principalmente, pela destruição que causaram como o ataque japonês a base naval de Pearl Harbor, a Batalha de Stalingrado, e o bombardeio atômico às cidades de Hiroshima e Nagasaki, que ocasionaram a destruição física de edifícios e abalou a economia, além de um grande número de 
morte de civis, bem como uma população faminta e cujos efeitos são sentidos até hoje.

\begin{abstract}
As maiores crueldades de nosso século foram as crueldades impessoais decididas a distância, de sistema e rotina, sobretudo quando podiam ser justificadas como lamentáveis necessidades operacionais. Assim o mundo acostumou-se à expulsão e matança compulsórias em escala astronômica, fenômenos tão conhecidos que foi preciso inventar novas palavras para eles: sem Estado (apátrida) ou genocídio. (HOBSBAWM, 1995, p. 57)
\end{abstract}

Com tamanha destruição, a $2^{a}$ Guerra Mundial teve seu fim, segundo Mocelin (2009), na Europa com a invasão de Berlim pelos Sovietes em 7 de maio de 1945. Os líderes do Fascismo e do Nazismo morreram no mesmo ano: Mussolini foi fuzilado e Hitler suicidou-se. Na Ásia, após os bombardeios atômicos nas cidades de Hiroshima e Nagasaki com cerca de 300 mil mortos, o Japão assina a rendição aos EUA em 15 de agosto de 1945.

\title{
O recorte temático: os bombardeios aéreos
}

Um dos fatores que contribuíram para que a escala de destruição da $2^{a}$ Guerra Mundial fosse tão grande foi o poder aéreo. As tecnologias de aviação nesse período haviam se aperfeiçoado muito em relação à Primeira Guerra Mundial. Não só a tecnologia, mas também as estratégias de guerra passaram por uma revisão, o poder aéreo então passou a ser considerado uma contribuição para a vitória.

O investimento nessa tecnologia foi grande, mas era justificado pela crença de que esse seria um meio mais econômico, até mesmo, em termo de vidas. A tática mais utilizada com a aviação era o bombardeio estratégico, que buscava precisamente atingir alvos de fundamental importância para os inimigos, como ferrovias, refinarias, fábricas, entre outros. 
Nesse período houve vários expoentes dentro da aviação, um deles foi a Luftwaffe, força aérea alemã criada em 1935 por Adolf Hitler, foi de grande importância na rápida conquista da Europa e também contribuiu na criação do conceito de Blitzkrieg - a guerra relâmpago - que consistia em ataques rápidos e em surpresa ao inimigo.

Um país que investiu em grande escala no poder aéreo foram os Estados Unidos, sua força aérea AAF teve maior investimento após o ataque dos japoneses à Pearl Harbor. Além de inúmeros bombardeios estratégicos direcionados à Alemanha, o bombardeio nuclear das cidades de Hiroshima e Nagasaki demonstrou o quanto a guerra aérea foi destrutiva.

Queriam sair do chão, voar como os pássaros, ver o país lá do alto, viajar mais rápido do que qualquer um que estivesse preso ao solo. E o avião, mais do que a luz elétrica, mais do que a máquina a vapor, mais do que o telefone, mais do que o automóvel, mais até do que a imprensa, separava o passado do futuro. O avião libertara a humanidade do julgo da terra e Ihe abrira o domínio dos céus. (AMBROSE, 2005, p. 26)

Para o historiador Eric Hobsbawm (1995) a guerra aérea trouxe um caráter de impessoalidade ao combate, as tecnologias afastavam as pessoas que se transformavam em apenas alvos. Segundo o historiador inglês:

Outro motivo, porém, era a nova impessoalidade da guerra, que tornava o matar e estropiar uma conseqüência remota de apertar um botão ou virar uma alavanca. A tecnologia tornava suas vítimas invisíveis, como não podiam fazer as pessoas evisceradas por baionetas ou vistas pelas miras de armas de fogo. [...]. Lá embaixo dos bombardeios aéreos não estavam as pessoas que iam ser queimadas e evisceradas, mas somente alvos. Rapazes delicados, que certamente não teriam desejado enfiar uma baioneta na barriga de uma jovem aldeã grávida, podiam com muito mais facilidade jogar altos explosivos sobre Londres ou Berlim, ou bombas nucleares em Nagasaki. Diligentes burocratas alemães, que certamente teriam achado repugnante tanger eles próprios judeus mortos de fome para abatedouros, podiam organizar os horários de trem para o abastecimento regular de comboios da morte para os campos de extermínio poloneses, com menos senso de envolvimento pessoal. As maiores crueldades de nosso século foram as crueldades impessoais decididas à distância, de sistema e rotina, sobretudo quando podiam ser justificadas 
como lamentáveis necessidades operacionais. (HOBSBAWM, 1995, p. 57)

Para Hobsbawm (1995), a "guerra em massa" demandava uma grande produção e, nesse sentido, foram feitos diversos investimentos em tecnologia bélica, como é o caso dos bombardeios aéreos que forneciam um caráter de impessoalidade ao conflito a tecnologia afastava as pessoas, que se transformavam em meros alvos de suas bombas.

\section{Música e ensino de história}

De acordo com Almeida (1994), a contemporaneidade, vive ainda, numa sociedade oral, ou seja, em que se lê pouco, mas em compensação se ouve, vê e fala muito. Ainda segundo o autor, os recursos multi-midiáticos estão acessíveis aos alunos fora da escola, que muitas vezes ainda se mantém desatualizada, presa ao currículo.

Essa compreensão de que a escola não é a única instituição formadora dos alunos, pois ela interage com diferentes meios de comunicação em massa, possibilita que os professores façam uso de recursos midiáticos nas aulas de História visando a aproximação do conteúdo escolar com elementos presentes no universo do aluno, como é o caso da música.

A música vem conquistando espaço nas pesquisas históricas como expressão cultural de um tempo. O professor deve explicitar, ao trabalhar com esse tipo de fonte em sala de aula, demonstrar aos alunos que essas músicas "não se constituem num discurso neutro, mas identificam o modo como, em diferentes lugares e em diferentes tempos, uma determinada realidade social é pensada e construída". (ABUD, 2005, p. 313). Segundo Oliveira (2009), para se fazer a análise de uma música como objeto de pesquisa é necessário estar atento não só a sua letra, mas também á aspectos como sua sonoridade, entonação, instrumentos utilizados, entre outros, já que a música não é composta apenas por suas letras.

Já para o historiador Marcos Napolitano (2002), sugere em seu livro História \& Musica algumas propostas metodológicas para a análise de 
músicas, segundo ele é importante realizar uma articulação entre "texto" e "contexto", ou seja, além da análise da canção deve-se apontar o tempo e espaço no qual ela foi produzida. Com viés multidisciplinar, a metodologia proposta por Napolitano consiste na análise da estrutura geral da canção, observando os parâmetros poéticos e os parâmetros musicais. Sendo o primeiro constituído pela letra, o seu tema, suas rimas, a utilização de figuras de linguagem, entre outros, e o segundo composto pelo ritmo, gênero musical e instrumentos utilizados. O autor também aponta a importância da performance, ou seja, da interpretação do cantor/banda, que interferem na maneira que o ouvinte receberá a mensagem transmitida na música.

O ponto de partida de qualquer análise é o resultado geral de uma estrutura poético-musical (no caso da canção) que chega até os nossos ouvidos pronta e acabada, bem ou mal resolvida, mais ou menos complexa, pouco ou muito bem articulada em suas diversas partes. (NAPOLITANO, 2002, p. 80-81)

Diante disso, a elaboração do material didático visando a utilização de músicas como recurso pedagógico em sala de aula, buscou a aproximação do conteúdo escolar com o cotidiano do aluno. Entendendo que:

A vivência cotidiana do aluno, seus contatos pessoais com familiares, amigos, a interação com a mídia levam-no a formular conceitos espontâneos que carecem de formas de explicitação a ser construídas no processo de aprendizagem formal. Nesse processo, os mesmos instrumentos que levam à construção dos conceitos espontâneos podem ser retomados para a caminhada em direção à construção dos conceitos científicos. (ABUD, 2005, p. 313)

Para tanto, foi produzido o material didático que consistiu em uma cartilha que continha as letras das músicas selecionadas e suas traduções, textos explicativos sobre o que foi a $2^{a}$ Guerra Mundial, o papel que a aviação desempenhou durante esse período, uma breve história do Heavy Metal e das bandas cujas músicas foram utilizadas. 


\section{Música e Heavy Metal}

De acordo com Lopes (2006) em sua tese de doutorado intitulada "Heavy Metal no Rio de Janeiro e dessacralização de símbolos religiosos: A música do demônio na cidade de São Sebastião das Terras de Vera Cruz" o Heavy Metal foi um dos estilos que nos anos 2000 menos sofreram impactos da queda de vendas na indústria fonográfica brasileira, em decorrência da disponibilidade de músicas na internet para download. Ele também ressalta que a banda brasileira mais conhecida internacionalmente e com maior vendagem no exterior pertence ao estilo Heavy Metal, o Sepultura formado no ano de 1984 em Minas Gerais.

O estilo musical Heavy Metal surgiu no fim da década de 1960 e início da de 1970, na Inglaterra e nos EUA, a banda considerada como a primeira do gênero é o Black Sabbath. Hoje o estilo se divide em vários sub-gêneros como o Thrash Metal, Black Metal, Death Metal, Folk Metal, entre muitos outros.

A expressão Heavy Metal é utilizada para designar além do estilo musical, um grupo de elementos tóxicos da Tabela Periódica dos elementos químicos e na linguagem bélica para designar a artilharia pesada. O termo foi primeiramente utilizado na música "Born to be wild" da banda Steppenwolf em 1968 que se tornou uma espécie de hino dos motociclistas e há hipóteses que a utilização da expressão "Heavy Metal thunder" nessa música inspirou o nome que passou a ser empregado para designar $\mathrm{o}$ gênero musical.

Segundo o autor Lopes (2006) as principais características de sonoridade e temas das músicas de Heavy Metal são:

[...] a guitarra hiper distorcida, grave nos refrões das músicas, ou "riffs" (utilizando os chamados "Power chords", acordes geralmente de duas notas graves, num intervalo de uma quarta ou uma quinta, obrigatoriamente com o efeito de distorção, que produzem acusticamente tons resultantes, gerando mais que as duas notas tocadas, segundo Walser, 
1993:43) e aguda nos muitas vezes longos e hiper velozes solos; o baixo tocado nas cordas mais graves e geralmente veloz; a bateria rápida e tocada de maneira vigorosa, geralmente com mais peças que em outros gêneros; os vocais emotivos e agressivos, muitas vezes também com um elemento de distorção; a extrema altura do som em shows e em audições privadas; as temáticas das letras políticas, antibelicistas, sobre desajuste social, com alertas contra o abuso de álcool e outras drogas, hedonistas ou clamando ou festejando a noção de "liberdade", místicas, sombrias, satânicas, de fantasia. (LOPES, 2006, p. 25-26)

Esse estilo musical além de ser caracterizado pela sonoridade, considerada uma mistura de blues com rock psicodélico e música erudita, também é caracterizado por conquistar público de várias idades, que geralmente começam a escutá-lo na juventude e continuam por muitos anos: O Heavy Metal surgiria então como um retorno do rock a determinadas características musicais e temáticas de um tipo de blues (como referências ao hedonismo e ao diabo), misturado ao rock psicodélico e temperado (fortemente) e alterado pela noção de peso. (LOPES, 2006, p. 114)

No que se refere às temáticas das letras, há uma grande variação que é diferenciada de acordo com os subgêneros, que fazem referência a assuntos como religião, fantasia, política, entre muitos outros. Essa multiplicidade de temas abordados pelo Heavy Metal proporcionam uma grande quantidade de músicas que podem ser utilizadas como objeto de análise em sala de aula.

\section{O Heavy Metal e a musicalidade em sala de aula}

No material didático elaborado foram propostas cinco questões para os alunos responderem, ao total o grupo composto por nove alunos devolveram as suas folhas de resposta. Uma das características principais nas respostas dos alunos é o uso da tecnologia como sinônimo do maléfico, na maioria das respostas eles relacionam o tema com seu poder destrutivo. 
$\mathrm{Na}$ questão número um, foram colocadas duas frases de autores que embasaram a elaboração da cartilha, sendo eles Hobsbawm e Ambrose, e era indicado aos alunos que após a leitura dessas, eles deveriam escrever um parágrafo identificando a importância da aviação durante a $2^{a}$ Guerra Mundial.

A primeira frase era: "A guerra aérea também atingiu a maioridade na Segunda Guerra Mundial, notadamente como um meio de aterrorizar civis" (HOBSBAWM, 1995, p. 36). A segunda frase era a citação presente na página 4 desse artigo.

Nas respostas dos alunos percebe-se que a questão do poder destrutivo proporcionado pelos bombardeios aéreos foi bastante mencionado, a relação entre a evolução da aviação e os extermínios em massa ocasionados pelos bombardeios estratégicos também foram ressaltados. Segundo um dos alunos: "Os autores querem falar da evolução que existiu na aviação da Primeira para a Segunda Guerra Mundial e mostrar que era só apertar um botão para dizimar exércitos e cidades."

A maioria das respostas para essa questão abordaram os aspectos destrutivos dos bombardeios aéreos, como o ato de acionar um botão poderia causar grandes extermínios. Os alunos para responder essa questão utilizaram vários trechos do texto explicativo sobre os bombardeios aéreos da Segunda Guerra Mundial que compunham a cartilha.

O parágrafo a seguir presente no texto da apostila foi bastante mencionado nas respostas: "Nesse período era uma grande honra para um jovem ser da força aérea, isso garantia status na sociedade e a possibilidade de não ir para uma trincheira, além disso, significava que não estariam cara a cara com as pessoas (a menos que fossem capturados), para os tripulantes dos aviões ao bombardearem uma fábrica não estavam atingindo civis, mas sim um alvo que representava seu inimigo."

A questão número dois se estruturava em: "Lembra da frase do Einstein que está no início de sua cartilha? 'Eu não sei com que armas a Terceira Guerra Mundial será lutada, mas a Quarta Guerra Mundial será 
lutada com paus e pedras. ${ }^{3}$ Escreva, em sua opinião, o que ele quis dizer com essa frase." Esperava-se que os alunos demonstrassem o quanto o poder bélico da $2^{a}$ Guerra Mundial mostra que as inovações tecnológicas podem ser altamente destrutivas.

Nas respostas pode-se perceber que tal objetivo foi alcançado, já que a maioria dos alunos relacionou o poder bélico com a destruição, para eles isso reflete como "a inteligência humana é usada de maneira negativa" e que a "tendência do poder bélico é uma destruição maior". Eles também sinalizam a dificuldade de recuperação no pós-guerra devido à devastação causada por essa tecnologia "extraordinária" dos armamentos. Nas palavras dos alunos: "Na Segunda Guerra Mundial já houve uma enorme tecnologia com armas, aviões, bombardeios, com isso houve também muita destruição e muitas mortes de soldados e civis. Se pensarmos numa Terceira Guerra, imagine como seria a tecnologia usada."

Outra aluna também aponta a questão do pós-guerra: "Depois de tanta violência, e tanto gasto com armamentos, a destruição seria tão grande a ponto de que para recuperar tudo de novo seria quase impossível." Esses apontamentos dos alunos podem ser relacionados com aquilo que Bauman (2008) chama de "Globalização Negativa", na qual: "A humanidade tem agora todas as armas necessárias para cometer o suicídio coletivo, seja por vontade própria ou falha- para aniquilar a si mesma, levando o resto do planeta à perdição." (BAUMAN, 2008, p. 96)

É interessante observar que para muitos alunos, pela maneira com que escrevem suas respostas, a $3^{a}$ Guerra Mundial apontada por Einstein na frase é quase uma certeza e não apenas uma possibilidade. Nas discussões eles argumentaram que a probabilidade que uma $3^{a}$ Guerra Mundial venha a acontecer é muito grande, não só pela preparação que os países possuem em termos de desenvolvimento bélico e de táticas, mas também pelas questões de política externa que vem acontecendo atualmente.

Nas questões 3 e 4, buscava-se que os alunos utilizassem trechos das músicas em suas respostas apontando as diferentes abordagens de uma

\footnotetext{
${ }^{3}$ Esta frase é atribuída á Einstein, fonte: ANTUNES, C. Resenha do livro: A crise Estrutural do Capital de István Mészáros. Germinal: Marxismo e Educação em Debate, Londrina, v.1, n.2, p.144-146, jan. 2010.
} 
música para outra, já que apesar das duas músicas tratarem sobre aviões da RAF (Força Aérea Britânica), o modo que o narrador de cada uma narra os combates é diferente. Abaixo as letras ${ }^{4}$ das duas músicas, Aces High ${ }^{5}$ e Bomber ${ }^{6}$ :

\section{Letra Aces High}

There goes the siren that warns of the air raid

Then comes the sound of the guns sending flak

Out for the scramble, we've got to get airborne

Got to get up for the coming attack

Jump in the cockpit and start up the engines

Remove all the wheelblocks, there's no time to waste

Gathering speed as we head down the runway

Got to get airborne before it's too late

Running, scrambling, flying

Rolling, turning, diving

Going in again

Running, scrambling, flying

Rolling, turning, diving

Run,

Live to fly, fly to live, do or die

Won't you

Run, live to fly, fly to live

Aces high

Move in to fire at the mainstream of bombers

Let off a sharp burst and then turn away

\section{Tradução \\ Altura dos ases}

Lá vai a sirene que avisa do ataque aéreo

Depois vem 0 som das armas antiaéreas

Saindo para a confusão, temos de decolar

Temos de nos preparar para o ataque que vem

Pular na cabine e ligar os motores

Remover as travas das rodas,

Não há tempo a perder

Tomando velocidade

Enquanto avançamos pela pista

Temos de decolar antes que seja

tarde demais

Correndo, disputando, voando

Rolando, girando, mergulhando, indo de novo

Correr, viver para voar,

Voar para viver, fazer ou morrer

Correr, viver para voar,

Voar para viver.

Alturas dos ases.

Movendo para atirar na formação de bombardeios

Soltar uma rajada certeira e depois dar a volta

\footnotetext{
4 Letras disponíveis em: http://letras.terra.com.br/iron-maiden/19286/traducao.html e http://letras.terra.com.br/motorhead/121518/traducao.html Acesso em: 19/03/2011.

5 ACES HIGH. Iron Maiden. In: album Powerslave. EUA: EMI, 1984.

${ }^{6}$ BOMBER. Motörhead. In: álbum Bomber. Reino Unido: Bronze Records, 1979.
} 
Roll over, spin round to come in behind them

Move to their blindsides and firing again

Bandits at 8 o'clock are moving behind us

Ten ME-109's out of the sun

Ascending and turning, our spitfires to face them

Heading straight for them I press down my guns.

Rolling, turning, diving

Rolling, turning, diving

Going in again

Rolling, turning, diving

Rolling, turning, diving

Run,

Live to fly, fly to live, do or die

Won't you

Run, live to fly, fly to live
Rodear por cima, girar e vir por detrás deles

Mover para seus pontos sem visão

E atirar novamente

Inimigos às 8 horas (1) se movem por detrás de nós

Dez me-109 (2) vindo da direção do sol

Subindo e girando

Nossos spitfires (3) para encará-los

Indo em direção a eles eu aciono minhas armas

(1) direções são informadas por aviadores usando as direções dos ponteiros de relógio. $8 \mathrm{~h}$ no caso significa aviões inimigos vindos de trás pela esquerda.

(2) me-109s são modelos de aviões alemães.

(3) spitfires (cuspidores de fogo) eram as aeronaves usadas pelos ingleses.

\section{Tradução Bombardeiro}

Ain 't a hope in hell,

Nothing's gonna bring us down,

The way we fly,

Five miles off the ground,

Because we shoot to kill,

And you know we always will,

It's a Bomber

Scream a thousand miles,

Feel the black death rising moan,

Firestorm coming closer,

Napalm to the bone,

Because, you know we do it right,

A mission every night,

It's a Bomber

No night fighter,

Gonna stop us getting through,

The sirens make you shiver,
Não há esperança no inferno,

Nada vai nos derrubar,

Da forma como voamos,

A cinco milhas do chão,

Porque atiramos para matar,

E como sabe assim sempre faremos,

É um bombardeiro

Um grito a milhares de milhas, Sinta a morte negra se espalhando, A tempestade de fogo chegando perto, Napalm (1) até os ossos, Pois, você sabe nós fazemos direito, Uma missão por noite, É um bombardeiro

Sem batalhas no escuro, Tentem nos parar de ir adiante, As sirenes vão lhe dar tremores, 
You bet my aim is true, Because, you know we aim to verdadeiro, please, Bring you to your knees, It's a Bomber
Podem apostar que meu objetivo é Porque nosso objetivo é agradar, Deixá-los de joelhos, É um bombardeiro

(1) conjunto de líquidos inflamáveis à base de gasolina gelificada, utilizados como armamento militar

A Aces High do Iron Maiden trata de um ataque aéreo que o piloto está indo enfrentar, ou seja, o inimigo o está atacando e ele se defende visando sua sobrevivência, enquanto que na música Bomber do Motörhead o piloto está indo com sua tripulação para uma missão de bombardeio, buscando o aniquilamento do inimigo.

Essas relações foram apontadas pelos alunos principalmente nesses trechos das músicas: Aces High - "Voar para viver", "Temos de nos preparam para o ataque que vem". Nesses trechos os alunos identificaram que passam a ideia do dia-a-dia de um piloto na busca de defesa.

Nessa música os alunos também apontaram a maneira quase mecânica que o narrador descreve a preparação dos pilotos para um combate, utilizando o seguinte trecho para justificar sua resposta: "Pular na cabine e ligar os motores / Remover as travas das rodas / Não há tempo a perder".

Na segunda música, Bomber, o trecho mais assinalado pelos alunos foi: "Porque atiramos para matar", no qual eles apontam o ataque a um território inimigo com sentimento de batalha, ou seja, nas palavras de uma aluna: "esse trecho retrata o soldado de maneira ofensiva, com sede de guerra e vontade de matar."

Outro trecho dessa música que também apareceu em muitas respostas foi o: "Um grito a milhares de milhas / Sinta a morte negra se espalhando,", fazendo ligação com a questão do distanciamento do ataque que o poder aéreo proporcionava.

$\mathrm{Na}$ questão número cinco, o objetivo era que os alunos reunissem todo o conhecimento adquirido através da cartilha em um texto que 
também demonstraria o posicionamento do aluno numa suposta situação em que ele é o piloto da aeronave durante a guerra.

Devido ao pouco tempo restante, as respostas obtidas nessa questão vieram em forma de um parágrafo ao invés de um texto. Nesses parágrafos as questões mais abordadas foram a descrição do dia-a-dia dos pilotos, a relação do nacionalismo presente nas ações dos pilotos e seus deveres com a nação. Alguns alunos também falaram sobre a relação da destruição possibilitada pelo poder aéreo e a morte de pessoas inocentes, descrevendo-as com sentimento de culpa.

Um dos alunos escreveu o que seria uma carta contando o que imagina através dos textos lidos, ser a realidade de um piloto numa guerra: "Estamos em alerta, não sabemos o que vai acontecer, a qualquer momento a sirene pode tocar para nos defendermos ou iniciarmos uma missão. Não durmo mais a noite de tanto pensar nas milhares de pessoas que posso ter matado, sinto o dever de defender minha pátria, mas eu tenho medo do que pode acontecer."

A relação do uso da tecnologia para o mal foi bastante mencionada pelos alunos, e a relação dessa tecnologia naquele período com a tecnologia que os países possuem hoje é demonstrada na certeza com que eles expõem sobre uma possível terceira Guerra Mundial. É como Bauman (2008) fala sobre a questão do medo na sociedade contemporânea:

O medo é seguramente o mais sinistro dos muitos demônios que se aninham nas sociedades abertas de nossa época. Mas é a insegurança do presente e a incerteza do futuro que criam e alimentam o mais aterrador e menos suportável de nossos medos. A insegurança e a incerteza, por sua vez, nascem de um sentimento de impotência: não parecemos mais estar no controle, sejam sozinhos, em grupo ou coletivamente, os assuntos de nossas comunidades, da mesma forma que não estamos no controle dos assuntos do planeta_ e nos tornamos cada vez mais conscientes de que não é provável que nos livremos da primeira desvantagem enquanto permitirmos que a segunda persista (BAUMAN, 2008, p. 167).

Nas respostas percebe-se que a questão de destruição que a aviação e os bombardeios aéreos proporcionaram na $2^{a}$ Guerra Mundial foi o assunto que os alunos mais se interessaram e debateram. Esses exercícios 
e os diálogos estabelecidos com os alunos durante a aplicação da cartilha servem para compreendermos como os alunos assimilaram aquilo que foi exposto no material didático.

\section{Considerações finais}

A utilização da música como recurso pedagógico na aula de História contribui não apenas como entretenimento, na diferenciação das aulas que na maioria das vezes são pautadas somente no livro didático, mas também e, principalmente, na função de utilizar o conhecimento que os alunos adquirem em outros locais além da escola, para contribuir na construção do conhecimento histórico.

Além de perceber que os alunos se mostram muito mais interessados numa aula que siga esses aspectos de utilização de recursos multimidiáticos, a participação deles também é maior, não apenas nos exercícios, mas, em grande medida, na discussão em sala de aula. Nesse trabalho pode-se observar que o assunto desenvolvido no mini-curso e presente na cartilha ficou mais perceptível aos alunos através da música. E que isso despertou neles a vontade de procurar por mais músicas que tratassem do assunto.

Nas respostas analisadas, no que se refere ao tema infere-se que os alunos apontam muito a questão da evolução da tecnologia bélica e da violência e destruição que esta pode causar. Questões como essa, foram bastante debatidas durante a aplicação do material, e eles se mostraram bastante preocupados segundo uma aluna, com "a capacidade do ser humano de usar a sua inteligência de maneira negativa".

O material didático que utilizamos foi elaborado buscando unir o conhecimento formal do currículo escolar aos conceitos espontâneos formados pelo aluno através de suas vivências, como no caso dos recursos multi-midiáticos que estão acessíveis aos alunos fora da escola. Espera-se que as reflexões aqui levantadas contribuam no entendimento da importância da utilização da música como recurso pedagógico no ensino de 
história, com os exemplos dessa experiência e que também possibilite a oportunidade de elaborar novos questionamentos e discussões referentes ao tema.

\section{Referências}

ABUD, K. M. Registro e representação do cotidiano: a música popular na aula de história. Cad. Cedes, Campinas, v. 25, n. 67, p. 309-317, set/dez. 2005.

ALMEIDA, M. Imagens e Sons: A nova cultura oral. São Paulo: Cortez, 1994.

AMBROSE, S. Azul sem fim: os homens e rapazes que conduziram os B-24 aos céus da Alemanha Nazista. Rio de Janeiro: Bertrand Brasil, 2005.

ARNAUT, L.; MOTTA, R. P. S. A segunda grande guerra: do nazi-facismo à guerra fria. São Paulo: Atual, 1994.

BAUMAN, Z. Medo Líquido. Rio de Janeiro: Jorge Zahar Ed., 2008. 1998. O mal estar da pós-modernidade. Rio de Janeiro: Jorge Zahar Ed.,

BRITO, E. Z. C. de. História e música: tecendo memórias, compondo identidades. Revista Textos de História, Brasília, v. 15, n., 2007.

FAUSTO, B. O pensamento nacionalista autoritário: (1920-1940). Rio de Janeiro: Jorge Zahar Ed., 2001.

GÓES, P. da S. A utilização da música nas aulas de história com os alunos do $8^{\circ}$ ano. Anais do V Colóquio Internacional Educação e Contemporaneidade, São Cristovão- SE, setembro de 2011.

HOBSBAWM, E. Era dos Extremos: o breve século XX: 1914-1991. São Paulo: Companhia das Letras, 1995.

HOWARD, M. O conceito de poder aéreo: uma avaliação histórica. Revista Air and Space Power. Disponível em:

http://www.airpower.maxwell.af.mil/apjinternational/apjp/1996/4tri96/howard.html Acesso em: 25/03/11.

LOPES, P. A. L. Heavy Metal no Rio de Janeiro e dessacralização de símbolos religiosos: A música do demônio na cidade de São Sebastião das Terras de Vera Cruz. Tese (Doutorado em Antropologia Social) Museu Nacional da Universidade Federal do Rio de Janeiro. Rio de Janeiro, 2006.

MOCELIN, K. D. Memórias de guerra: a trajetória da FEB na $2^{a}$ Guerra Mundial. Monografia, Universidade Tuiuti do Paraná. Orientação do Professor Osvaldo L. Meza Siqueira. Curitiba, 2009.

NAPOLITANO, M. História \& Música- história cultural da música popular. Belo Horizonte: Autêntica, 2002. 
OLIVEIRA, R. C. Cultura e vida social: um olhar sobre a produção musical rap e hardcore no Brasil contemporâneo. Revista Urutágua. Revista acadêmica multidisciplinar. Maringá, n. 18- mai/jun/jul/ago. 2009quadrimestral.

História, música e ensino ao ritmo dos excluídos: músicas engajadas e problemáticas sociais na contemporaneidade. Cadernos de História, Uberlândia, v. 15, n.1, p 137-149, set. 2006/set.2007.

PACHECO, L. T. "Som de macho": uma reflexão sobre identidade, masculinidade e alteridade entre os headbangers. Anais do VII seminário Fazendo Gênero. Florianópolis, 28, 29 e 30 de agosto de 2006. Disponível em: http://www.fazendogenero7.ufsc.br/ Acesso em 20/05/2009.

\section{Referências discográficas:}

IRON MAIDEN. Álbum Powerslave. EUA: EMI, 1984.

MOTÖRHEAD. Álbum Bomber. Reino Unido: Bronze Records, 1979.

Enviado pelos autores em 13 de Junho de 2012.

Aprovado em 09 de Julho de 2012. 